\title{
Intradermal Double-Layer Closure with Suture Knot Contained Within Incision: Easy, Fast, and Safe
}

\author{
Manuel Maia $\cdot$ Luis Azevedo
}

Published online: 17 September 2009

(C) Springer Science+Business Media, LLC and International Society of Aesthetic Plastic Surgery 2009

We read with great interest the recent article by Thomas C. Wiener [1]. About 12 years ago Maia introduced the intradermal double-layer closure technique with the suture knot contained within the incision. Since that time he has used it as his standard suture technique in more than 3000 cases that include different aesthetic surgery procedures. The technique consists of an intradermal double-layer closure with a deep and a superficial dermal running component that are in continuity (Figs. 1 and 2), with no intradermal orientation stitches (except in very large incisions, i.e., $>40 \mathrm{~cm}$ ). The final knot is placed deep within one end of the incision (Fig. 2). In our experience this technique is safe and fast and puts less artificial material inside the wound compared with conventional techniques that have internal knots and running suture. We reported very few cases of knot extrusion, which were probably caused by a superficial position of the knot, and there were no major consequences. Because of the results we have with our technique we do not see any significant advantage of the remote-knot technique, which has the disadvantage of a second scar, even if it is a small scar.

\section{Reference}

1. Wiener TC (2009) A modified incision closure for breast augmentation: remote-knot technique. Aesthetic Plast Surg 33: $110-112$

M. Maia $\cdot$ L. Azevedo $(\bowtie)$

Hospital Prelada, R. Sarmento Beires 153,

Oporto 4250-449, Portugal

e-mail: luisfilipeazevedo@gmail.com

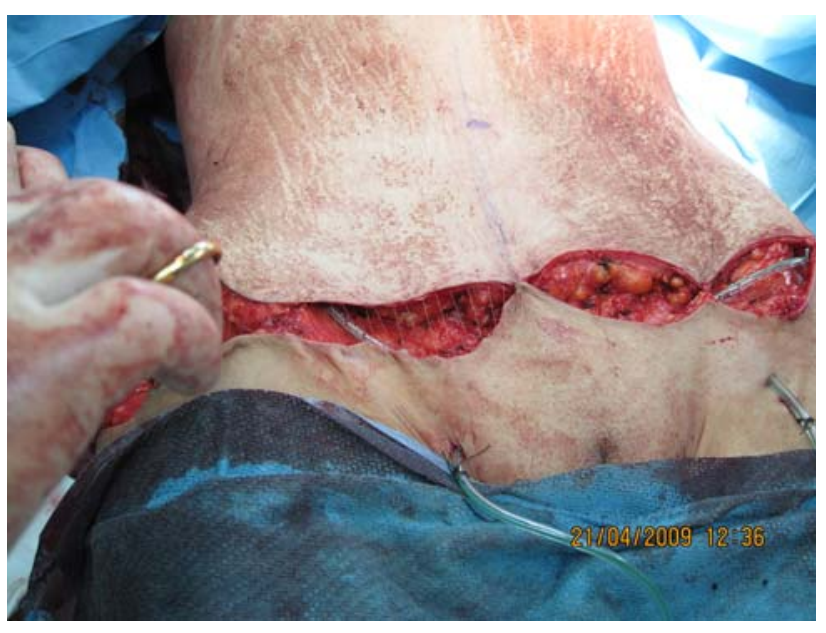

Fig. 1

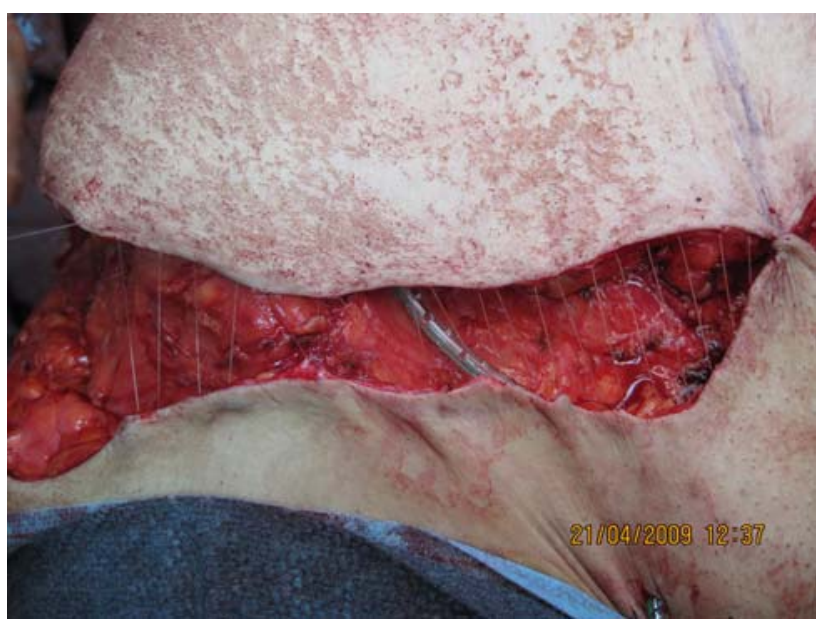

Fig. 2 